\title{
Investigation of Thermostressed State of Coating Formation at Electric Contact Surfacing of "Shaft" Type Parts
}

\author{
Olena V. Berezshnaya, ${ }^{1}$ Eduard P. Gribkov, ${ }^{2}$ and Valeriy D. Kuznetsov ${ }^{1}$ \\ ${ }^{1}$ Department of Surface Engineering, National Technical University of Ukraine "Kyiv Polytechnic Institute" (NTUU "KPI"), \\ Prospect Peremohy 37, Kyiv 03056, Ukraine \\ ${ }^{2}$ Automated Metal Forming Process and Machinery Department, Donbass State Engineering Academy, Shkadinova 72, \\ Donetsk Region, Kramatorsk 84313, Ukraine
}

Correspondence should be addressed to Olena V. Berezshnaya; elena.kassova07@gmail.com

Received 14 March 2016; Revised 28 July 2016; Accepted 6 September 2016

Academic Editor: Sutasn Thipprakmas

Copyright (c) 2016 Olena V. Berezshnaya et al. This is an open access article distributed under the Creative Commons Attribution License, which permits unrestricted use, distribution, and reproduction in any medium, provided the original work is properly cited.

\begin{abstract}
The forming of coating at electric contact surfacing is considered. The mathematical model of the coating formation is developed. The method of numerical recurrent solution of the finite-difference form of static equilibrium conditions of the selected elementary volume of coating is used. This model considers distribution of thermal properties and geometric parameters along the thermal deformation zone during the process of electric contact surfacing by compact material. It is found that the change of value of speed asymmetry factor leads to increasing of the friction coefficient in zone of surfacing. This provides the forming of the coating of higher quality. The limitation of the technological capabilities of equipment for electric contact surfacing is related to the size of recoverable parts and application of high electromechanical powers. The regulation of the speed asymmetry factor allows for expanding the technological capabilities of equipment for electric contact surfacing. The nomograms for determination of the stress on the roller electrode and the finite thickness of the coating as the function of the initial thickness of the compact material and the deformation degree are shown.
\end{abstract}

\section{Introduction}

The creation of a coating with the necessary operating characteristics is a perspective direction in the reconditioning of worn parts as well as improvement of their service life [1-5]. This allows for providing a wide range of surface characteristics for various operating conditions.

One of the most common technological processes of the reconditioning of the worn parts is arc welding, which achieves the desired working layer on the surface of the product but has a number of disadvantages too. Those include a significant change in the initial phase state of coating material and substantial thermal effect in material of a part [6-8]. At such technological reconditioning, the magnitude of the heat-affected zone causes the development of residual stresses in the material of which the part is made. This has a negative impact on its durability even though force or heat is not applied to it. During the exploitation of the parts reconditioned this way, the residual stresses are converted into exploitative residual stresses, which are the major cause of endurance reduce, cracks, and splits formation on the surface of product as well as of its deformation during production and exploitation. The coating technology based on the short-term heat influence allows avoiding the formation of the heat-affected zone of considerable size and thus the subsequent occurrence of the internal stresses. Such technologies include the electric contact method of surfacing of the coating with the specified operating characteristics, applied to the worn surfaces.

This method is a combination of short-term thermal and mechanical effects on the surfaced material located on the surface of a renewed rotating axisymmetric part, which allows for providing a tough coating. The conjoint plastic deformation of a renewed part together with adding material results in combination of the coating with the base metal. Currently, there are a lot of studies on the selection 
of the recommended composition of the compact material, providing the desired performance characteristics of the coating. However, because of the short duration of the electric contact surfacing, there are some difficulties in predicting the quality of the coating and its compliance with basic operation characteristics. That is why it is necessary to use the mathematical apparatus for analytical design of electric contact surfacing in order to optimize the basic parameters of this process to obtain the coating that best meets the specified requirements.

Authors in [9] proposed the mathematical model of the coating formation on the surface of cylindrical parts with electric contact wire surfacing. In the work of [10], there is a mathematical model of forming of sintered tape reinforced by metal grid for increasing mechanical properties using the electric contact seam welding. Normal contact stresses in thermal deformation zone are determined. In the work of [11], an adhesive strength of surfaced layer with amorphous underlayer is considered. Regression equations for determining of adhesive strength are received. Coefficient of welded spots overlapping is represented. The mathematical models of the stress-strain state of the material on the basis of the conjoint finite-difference solutions of the equations of static equilibrium and conditions of plasticity in the works [1214] are developed. This method is confirmed experimentally and widely used for solving this type of tasks. However, represented mathematical models are insufficiently reliable because of lack of consideration of the thermal state of material in thermal deformation zone.

The short-term thermomechanical exposure during the electric contact surfacing allows decreasing thermal influence on the coating and part material on the one hand and decreases the quality forecasting accuracy of the coating on the other hand. The adhesive strength of the coating to the part surface during the electric contact surfacing is an important quality indicator; thus, the task of developing technological methods to improve the adhesive strength is an actual problem.

\section{Prime Novelty Statement}

The formation of coating at electric contact surfacing of "shaft" type parts is investigated. The influence of the thermomechanic operating parameters on the coating formation on the surface of cylindrical part with predicted geometric parameters is investigated.

Based on the numerical recurrent solution of the finitedifference form of the static equilibrium conditions of selected elementary volume of the coating, mathematical model of coating formation was developed. Its peculiarity is the proper record of actual distribution of the thermal properties and geometric parameters on the length of thermal deformation zone during the process of electric contact surfacing by compact material. The problem of automated design of technological modes of electric contact surfacing is formulated and solved by using the developed mathematical model.

The method to improve the adhesive strength of the coating to the part surface by creation of the speed asymmetry during the electric contact surfacing by the compact material is proposed.

The influence of the speed asymmetry factor on the friction coefficient changing in thermal deformation zone in the zone of contact of part with compact material is investigated.

The impact of the speed asymmetry factor on the energy-power and thermal operating parameters' changing is proved.

Results of research can be used in the designing of equipment for electric contact surfacing, as well as in selection of optimal operating parameters of surfacing process.

\section{Theoretical Studies}

The mathematical model of electric contact surfacing of "shaft" type parts is developed on the basis of the numerical recurrence solution of the finite-difference form of static equilibrium conditions of selected elementary volumes [1518]. The plastic deformation zone $a_{1} c_{1} c_{2} a_{2}$ is divided on the finite set of elementary volumes (Figure 1).

Due to the specific realization conditions of considered technology, we should point out that the circumferential speed of part 1 and compact material 2 at the outlet from the plastic deformation zone are equal; that is, $V_{2}=V_{1}$. That is why there is only a zone of the lag $L_{\lg 1}=L_{\mathrm{pl}}$ on the surface of the part. The tangential contact stresses $\tau_{x 1}$ have the same direction with the surfacing process at this zone. The circumferential speed of the roller electrode $V_{2}$ is a bit lower than surface speed $V_{1}$. The speed asymmetry factor is characterized by the ratio of $V_{2}=V_{1} / K_{v}$. This causes the formation of the zone of lag $L_{\lg 2}$ on the roller electrode. There is also a mixed zone $L_{m}$, in which tangential contact stresses $\tau_{x 2}$ are contradirectional with surfacing process (see Figure 1).

In addition to the abovementioned, a number of assumptions were adopted. The most important of them are the following.

(i) Deformation of compact material 2 (see Figure 1) is flat and set in time. The kinematics of plastic flow of the material obey hypothesis of flat sections. The normal axial stresses $\sigma_{x i}$ and performances of the double shift resistance $2 K_{x i}$ are changed only along the zone of plastic deformation.

(ii) On the length of each selected $i$ th elementary volume (Figure 2), the current values of the thicknesses $h_{x i}=h_{x i 1}$ $\cdots h_{x i 2}$, normal contact $p_{x i}=p_{x i 1} \cdots p_{x i 2}$, and tangential contact stresses $\tau_{x 2 i 1}=\tau_{x 2 i 1} \cdots \tau_{x 2 i 2}$ are changed linearly.

(iii) Analytical descriptions of tangential contact stresses $\tau_{x i 1}, \tau_{x i 2}$ are subordinate to plastic friction law proposed by Siebel and running as follows:

$$
\begin{aligned}
& \tau_{x 1}=2 K_{x} \mu_{x 1} ; \\
& \tau_{x 2}=2 K_{x} \mu_{x 2} .
\end{aligned}
$$

The value of double shift resistance of the compact material is determined with considering current values of degree, speed, and temperature of deformation. The current value 


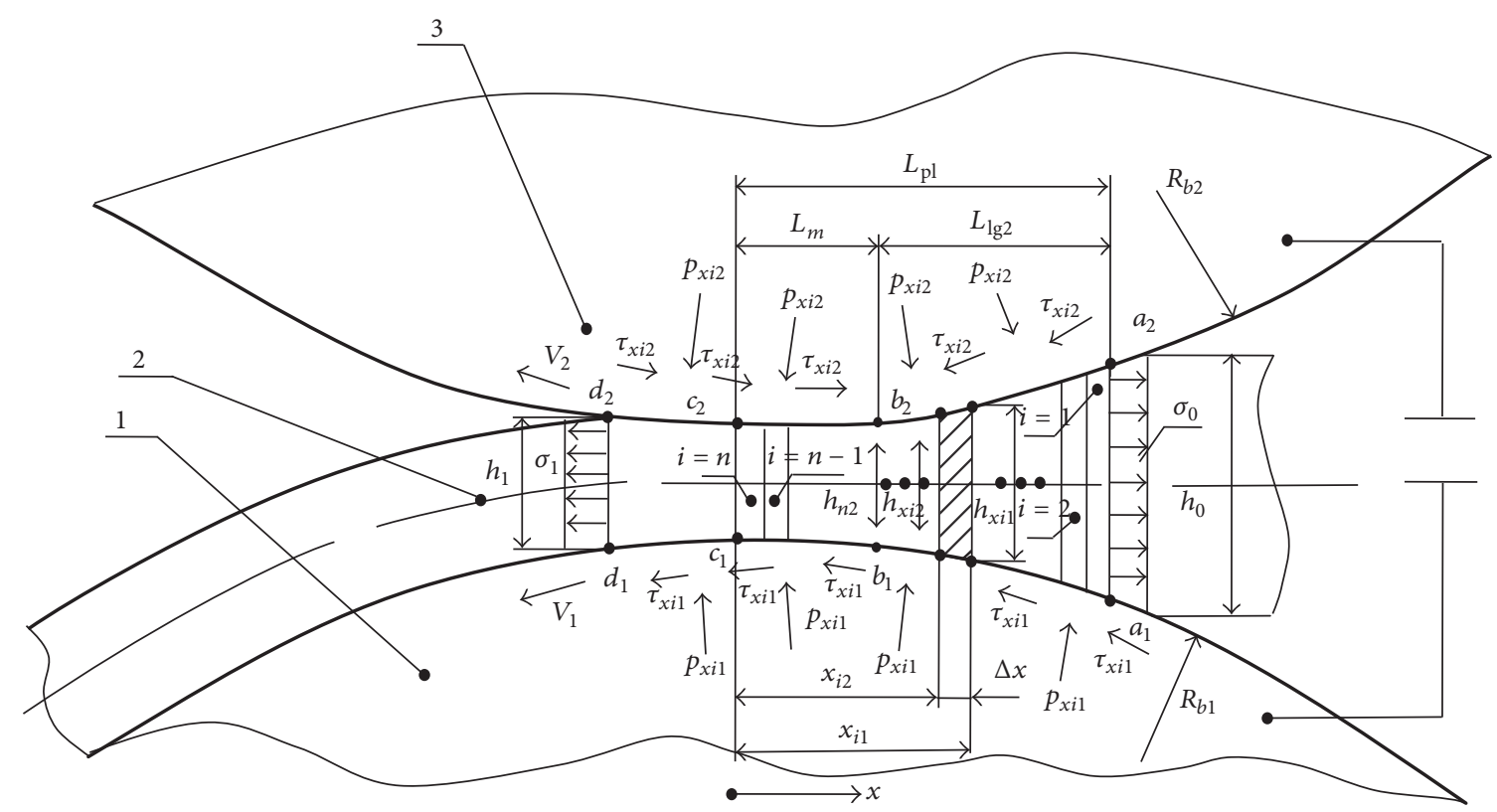

FIGURE 1: Design model for process of "shaft" type parts surfacing (1: part to be surfaced, 2: compact material, and 3: roller electrode).

of the plastic friction coefficients depends on the geometric coordinate $x$ as follows:

$$
\begin{aligned}
& \mu_{x 1}=\mu_{01}\left(\frac{x}{L_{\mathrm{pl}}}\right)^{a_{\mu 1}} \cdot \\
& \mu_{x 2}=\mu_{02}\left[\frac{\left(x-L_{m}\right)}{\left(L_{\mathrm{pl}}-L_{m}\right)}\right]^{a_{\mu 2}} \text { at } L_{m} \leq x \leq L_{\mathrm{pl}} ; \\
& \mu_{x 2}=-\mu_{02}\left[\frac{\left(L_{m}-x\right)}{L_{m}}\right]^{a_{\mu 2}} \text { at } 0 \leq x \leq L_{m} ;
\end{aligned}
$$

(iv) We neglect the presence of an elastic compression zone of surfaced compact material in sections at the inlet of the deformation zone, as well as the presence of the inertial components of the equilibrium conditions, due to their very low influence.

(v) Analytical description of the current thicknesses value $h_{x}$ of the coating along the zone of plastic deformation $L_{\mathrm{pl}}$ can be represented by a dependence:

$$
h_{x}=h_{1}+\left(h_{0}-h_{1}\right)\left(\frac{x}{L_{\mathrm{pl}}}\right)^{a_{h}}, \quad a_{h} \approx 2 .
$$

(vi) The total length of zone of the plastic deformation $L_{\mathrm{pl}}$, the volume of its partition step $\Delta x$, geometric coordinates of initial $x_{i 1}$, finite $x_{i 2}$ boundary sections for selected $i$ th elementary volume, and also the length of the mixed zone $L_{m}$ can be defined as

$$
L_{\mathrm{pl}}=\sqrt{2 R_{b 1} R_{b 2} \frac{\left(h_{0}-h_{1}\right)}{\left(R_{b 1}+R_{b 2}\right)}-\frac{\left(h_{0}-h_{1}\right)^{2}}{4}} ;
$$

$$
\begin{aligned}
& \Delta x=\frac{L_{\mathrm{pl}}}{n} ; \\
& x_{i 1}=L_{\mathrm{pl}}-\Delta x(i-1) ; \\
& x_{i 2}=x_{i 1}-\Delta x ; \\
& h_{n 2}=\frac{h_{1} V_{b 1}}{V_{b 2}}=h_{1} K_{v} ; \\
& L_{m}=\sqrt{2 R_{b 1} R_{b 2} \frac{\left(h_{n 2}-h_{1}\right)}{\left(R_{b 1}+R_{b 2}\right)}-\frac{\left(h_{n 2}-h_{1}\right)^{2}}{4}} .
\end{aligned}
$$

Given the nature of the assumptions and finite-difference record forms of the main components of the stress-strain state (see Figure 2), the condition of static equilibrium for selected $i$ th elementary volume in the axle projection of all the forces on the axis $x$ runs as follows:

$$
\begin{aligned}
\sum F_{x}= & \sigma_{x i 2} h_{x i 2}-\sigma_{x i 1} h_{x i 1} \\
& +\frac{\left(p_{x i 1}+p_{x i 2}\right)\left(h_{x i 1}-h_{x i 2}\right)}{2} \\
& +\frac{\left(2 K_{x i 1} \mu_{x 1 i 1}+2 K_{x i 2} \mu_{x 1 i 2}\right) \Delta x}{2} \\
& +\frac{\left(2 K_{x i 1} \mu_{x 2 i 1}+2 K_{x i 2} \mu_{x 2 i 2}\right) \Delta x}{2}=0
\end{aligned}
$$

where the positive values of the normal components for the stress tensors $\sigma_{x i 2}, \sigma_{x i 1}$ and $p_{x i 2}, p_{x i 1}$ correspond to the compression stresses. The opposite direction of tangential contact stresses $\tau_{x 2}$ is accounted by signs in analytical descriptions 


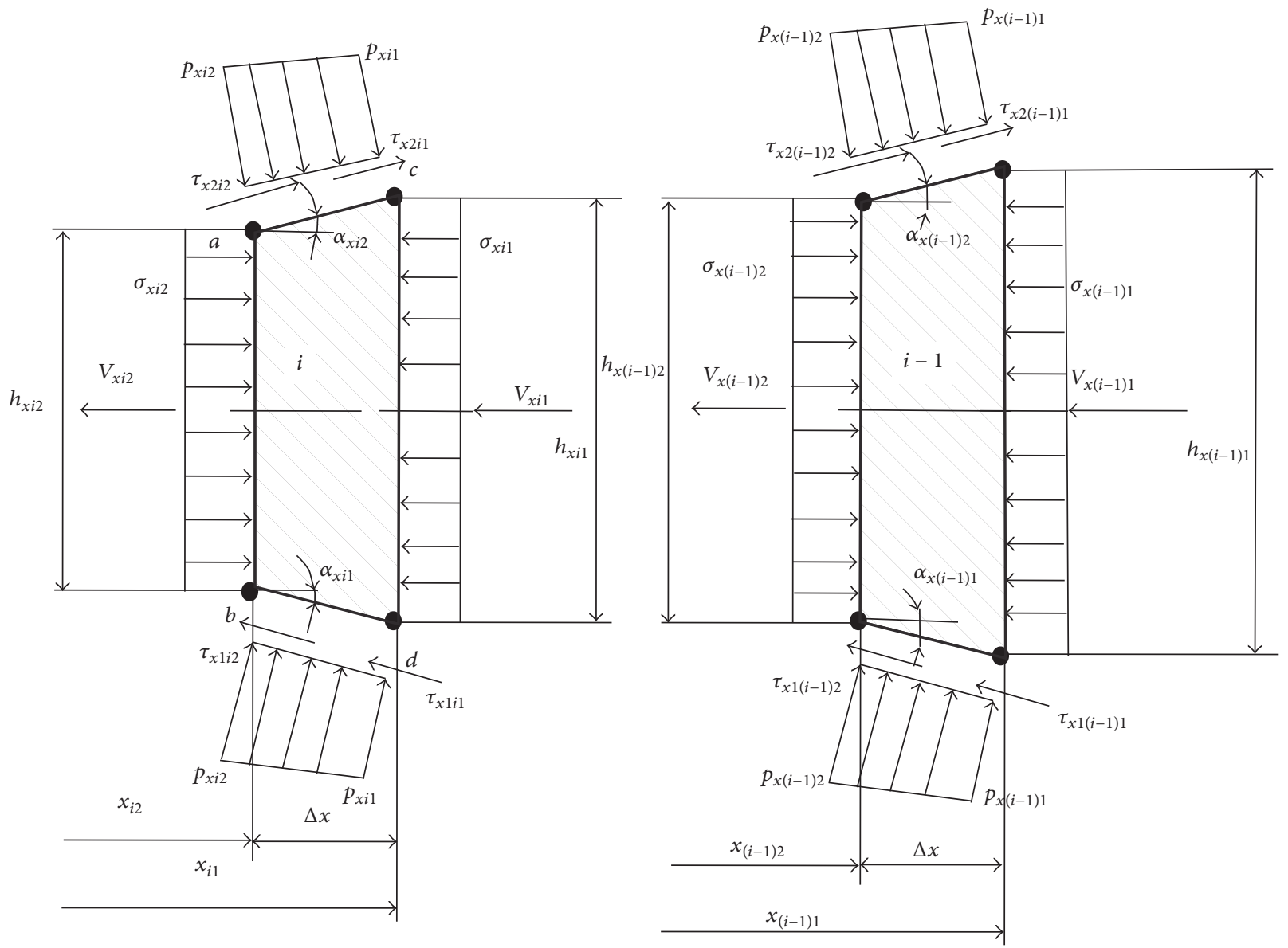

FIGURE 2: Design diagrams of elementary volumes of mathematical modeling of stress-strain state of the compact material.

(3)-(4) of current values for plastic friction coefficient values $\mu_{x 2}$.

The current levels of double shift resistance $2 K_{x i 1}$ and $K_{x i 2}$ are defined using the conventional methods. The values of the components $\Delta x, h_{x i 1}, h_{x i 2}, \mu_{x 1 i 1}, \mu_{x 1 i 2}, \mu_{x 2 i 1}, \mu_{x 2 i 2}$ are calculated according to $(2)-(7)$. Due to the recurrent scheme of solutions, the components of the stress states $\sigma_{x i 1}$ and $p_{x i 1}$ are known according to calculation results of the previous $(i-1)$ elementary volume (see Figure 2). Expression (8) is an equation with two unknown values $\sigma_{x i 2}$ and $p_{x i 2}$, which, following the engineering version of the plasticity condition, can be transformed as

$$
\left(p_{x i 2}-2 K_{x i 2}\right) h_{x i 2}-\sigma_{x i 1} h_{x i 1}
$$

$$
\begin{aligned}
& +\frac{\left(p_{x i 1}+p_{x i 2}\right)\left(h_{x i 1}-h_{x i 2}\right)}{2} \\
& -\frac{\left(2 K_{x i 1} \mu_{x 1 i 1}+2 K_{x i 2} \mu_{x 1 i 2}\right) \Delta x}{2} \\
& -\frac{\left(2 K_{x i 1} \mu_{x 2 i 1}+2 K_{x i 2} \mu_{x i 2}\right) \Delta x}{2}=0 .
\end{aligned}
$$

Equation (9) can be solved only for the one unknown value $p_{x i 2}$. In a final form, after the appropriate mathematical transformations, we obtain

$$
p_{x i 2}=\frac{\left\{2\left(\sigma_{x i 1} h_{x i 1}+2 K_{x i 2} h_{x i 2}\right)-p_{x i 1}\left(h_{x i 1}-h_{x i 2}\right)+\left[2 K_{x i 1}\left(\mu_{x i 1}+\mu_{x i 2}\right)+2 K_{x i 2}\left(\mu_{x i 1}+\mu_{x 2 i 2}\right)\right] \Delta x\right\}}{\left(h_{x i 1}+h_{x i 2}\right)},
$$

where normal axial stresses in the zone of plastic deformation, following the engineering version of plasticity conditions, can be defined as $\sigma_{x i 2}=p_{x i 2}-2 K_{x i 2}[12]$.
As the directions of recurrent circuit of solutions, the direction of the compact material is used. Taking this into account, the initial conditions for the first $i=1$ elementary 
volume and condition of communication at the transition from the calculation of the $i$ to the calculation $(i+1)$ were adopted in the following form:

$$
\begin{gathered}
\left.x_{i 1}\right|_{i=1}=L_{\mathrm{pl}} ; \\
\left.h_{x i 1}\right|_{i=1}=h_{0} ; \\
\left.\mu_{x 1 i 1}\right|_{i=1}=\mu_{01} ; \\
\left.\mu_{x 2 i 1}\right|_{i=1}=\mu_{02} ; \\
\left.\sigma_{x i 1}\right|_{i=1}=-\sigma_{0} ; \\
\left.p_{x i 1}\right|_{i=1}=0.0 ; \\
x_{(i+1) 1}=x_{i 2} ; \\
h_{x(i+1) 1}=h_{x i 2} ; \\
\mu_{x 1(i+1) 1}=\mu_{x 1 i 2} ; \\
\mu_{x 2(i+1) 1}=\mu_{x 2 i 2} ; \\
\sigma_{x(i+1) 1}=\sigma_{x i 2} ; \\
p_{x(i+1) 1}=p_{x i 2} .
\end{gathered}
$$

With the calculation of local characteristics for stressstrain state within zones of the plastic deformation of the compact material by numerical integration, there were certain forces $P$ and moments $M_{1}$ and $M_{2}$ of electric contact surfacing:

$$
\begin{aligned}
P & =\left[\sum_{i=1}^{n} \frac{\left(p_{x i 1}+p_{x i 2}\right) \Delta x}{2}\right] b ; \\
M_{1} & =\left[\sum_{i=1}^{n} \frac{\left(p_{x i 1} \mu_{x 1 i 1}+p_{x i 2} \mu_{x 12}\right) \Delta x}{2}\right] b R_{b 1} ; \\
M_{2} & =\left[\sum_{i=1}^{n} \frac{\left(p_{x i 1} \mu_{x 2 i 1}+p_{x i 2} \mu_{x 2 i 2}\right) \Delta x}{2}\right] b R_{b 1} .
\end{aligned}
$$

Modeling of thermal state of compact material in thermal deformation zone at electric contact surfacing is performed with considering of the compact material as unlimited plate [19]. Heating process is calculated according to the theory of heat conduction. The compact material is in temperature equilibrium with environment; that is, the temperature of the compact material is equal to the environment temperature $T_{o}$. Heat transfer between the surfaces of compact material and superficial layer in the thermal deformation zone proceeds in accordance with Newton's law [15]. Let us suppose that the origin of coordinates is in the middle of compact material. Then, $r$ is the half of the thickness of compact material; that is, $r=h_{x i 1} / 2$. To determine the heat distribution at any given moment, it is necessary to solve the differential Laplace equation of heat conduction:

$$
\frac{\partial T_{m}(y, t)}{\partial t}=a \frac{\partial^{2} T_{m}(y, t)}{\partial y^{2}} ; \quad(t>0 ;-r<y<r)
$$

with the initial and boundary conditions

$$
\begin{aligned}
T_{m}(y, 0) & =T_{o} \\
\frac{\partial T_{m}(0, t)}{\partial y} & =0 \\
-\lambda \frac{\partial T_{m}(r, t)}{\partial y}+\alpha\left[T(t)-T_{m}(y, t)\right] & =0
\end{aligned}
$$

With considering that $T(t)$ is the linear function of time, the boundary condition (16) can be obtained as

$$
-\frac{\partial T_{m}(r, t)}{\partial y}+\frac{\alpha}{\lambda}\left[T_{o}+g t-T_{m}(r, t)\right]=0 .
$$

Equations (13)-(17) can be solved by operating method with Laplace transformation:

$$
L\left[\frac{\partial T_{m}(y, t)}{\partial t}\right]=L\left[a \frac{\partial^{2} T_{m}(y, t)}{\partial y^{2}}\right],
$$

where

$$
L\left[T_{m}(y, t)\right]=\int_{0}^{\infty} T_{m}(y, t) e^{-s t} d t=T_{L}(y, s) .
$$

The differential equation of heat conductivity with considering of initial condition (14) after Laplace transformation can be solved as

$$
T_{L}^{\prime \prime}(y, s)-\frac{s}{a} T_{L}(y, s)+\frac{T_{o}}{a}=0 .
$$

The solution of (20) for image $T_{L}(y, s)$ can be defined as

$$
T_{L}(y, s)-\frac{T_{o}}{s}=A \operatorname{ch}\left(\sqrt{\frac{s}{a} y}\right)+B \operatorname{sh}\left(\sqrt{\frac{s}{a} y}\right),
$$

where $A$ and $B$ are constants, defined from boundary conditions (15) and (16).

According to symmetry condition (15),

$$
\begin{aligned}
T_{L}^{\prime}(0, s) & =\left[A \sqrt{\frac{s}{a}} \operatorname{sh}\left(\sqrt{\frac{s}{a}} y\right)+B \sqrt{\frac{s}{a}} \operatorname{ch}\left(\sqrt{\frac{s}{a}} y\right)\right]_{y=0} \\
& =B \sqrt{\frac{s}{a}}=0,
\end{aligned}
$$

where $B=0$.

Boundary condition (16) for image can be solved as

$$
\begin{aligned}
-T_{L}^{\prime}(r, s)+\frac{\alpha T_{o}}{\lambda s}+\frac{\alpha g}{\lambda s^{2}}-\frac{\alpha}{\lambda} T_{L}(r, s) & =0, \\
L\left[\frac{\alpha}{\lambda} g t\right] & =\frac{\alpha g}{\lambda s^{2}} .
\end{aligned}
$$

With considering $B=0$, (21) can be presented as

$$
\begin{gathered}
-A \sqrt{\frac{s}{a}} \operatorname{sh}\left(\sqrt{\frac{s}{a}} r\right)+\frac{\alpha T_{o}}{\lambda s}+\frac{\alpha g}{\lambda s^{2}}-\frac{\alpha T_{o}}{\lambda s} \\
-A \frac{\alpha}{\lambda} \operatorname{ch}\left(\sqrt{\frac{s}{a} r}\right)=0 .
\end{gathered}
$$


Then, constant $A$ can be defined from

$$
A=\frac{g}{s^{2}[\operatorname{ch}(\sqrt{s / a} r)+(\lambda / \alpha) \sqrt{s / a} \operatorname{sh}(\sqrt{s / a} r)]} .
$$

Thus, the solution for the image is

$$
\begin{aligned}
& T_{L}(y, s)-\frac{T_{o}}{s} \\
& =\frac{\operatorname{gch}(\sqrt{s / a} y)}{s^{2}[\operatorname{ch}(\sqrt{s / a} r)+(\lambda / \alpha) \sqrt{s / a} \operatorname{sh}(\sqrt{s / a} r)]} \\
& =\frac{\Phi_{1}(s)}{\Phi_{2}(s)} .
\end{aligned}
$$

Solution (26) is the ratio of generalized polynomials concerning $s$. Besides, the polynomial $\Phi_{2}(s)$ does not contain any constants; that is, solution responds to conditions of decomposition theorem. Thus, it can be used in solution of initial equation.

The decomposition theorem can be presented as

$$
L^{-1}\left[\frac{\Phi_{1}(s)}{\Phi_{2}(s)}\right]=\sum_{n=1}^{\infty} \frac{\Phi_{1}\left(s_{n}\right)}{\Phi_{2}^{\prime}\left(s_{n}\right)} e^{s_{n} t},
$$

where $s_{n}$ are the roots of polynomial $\Phi_{2}(s)$.

If $\Phi_{2}(s)=0$, then the roots are $s_{0}=0$, double root; $s_{n}=$ $-a \mu_{n}^{2} / r^{2}$, where $\mu=i \sqrt{s / a} r$-are the simple roots, defined from characteristic equation:

$$
\operatorname{ctg} \mu=\frac{\mu}{B i},
$$

where $\mathrm{Bi}=\alpha r / \lambda$, Biot criterion [20].

According to the decomposition theorem,

$$
L^{-1}\left[\frac{\Phi_{1}(0)}{\Phi_{2}(0)}\right]=g t+\frac{g}{2 a}\left[y^{2}-r^{2}\left(1+\frac{2 \lambda}{\alpha r}\right)\right] .
$$

The substitution of other roots $s_{n}$ into (27) allows for obtaining

$$
\begin{aligned}
\sum_{n=1}^{\infty} \frac{\Phi_{1}\left(s_{n}\right)}{\Phi_{2}^{\prime}\left(s_{n}\right)} e^{s_{n} t}= & \frac{g r^{2}}{a} \sum_{n=1}^{\infty} \frac{2 \sin \mu_{n}}{\left(\mu_{n}+\sin \mu_{n} \cos \mu_{n}\right)} \\
& \cdot \frac{1}{\mu_{n}^{2}} \cos \left(\mu_{n} \frac{y}{r}\right) \exp \left(-\mu_{n}^{2} \frac{a t}{r^{2}}\right) .
\end{aligned}
$$

Thus, the solution can be presented as

$$
\begin{aligned}
& T_{m}(y, t)-T_{o} \\
& =g t-\frac{g}{2 a}\left[r^{2}\left(1+\frac{2}{\mathrm{Bi}}\right)-y^{2}\right] \\
& \quad+\frac{g r^{2}}{a} \sum_{n=1}^{\infty} \frac{A_{n}}{\mu_{n}^{2}} \cos \left(\mu_{n} \frac{y}{r}\right) \exp \left(-\mu_{n}^{2} \mathrm{Fo}\right),
\end{aligned}
$$

where Fo $=a t / r^{2}$ is the Fourier criterion [20] and $A_{n}$ are the initial amplitudes, defined as

$$
A_{n}=\frac{2 \sin \mu_{n}}{\mu_{n}+\sin \mu_{n} \cos \mu_{n}} .
$$

Equation (31) allows for calculating the temperature $T_{m}(y, t)$ in any point of compact material in thermal deformation zone. The intensity of temperature increasing is characterized by the nondimensional heating rate, which is the Predvoditelev criterion [20]:

$$
\mathrm{Pd}=\left(\frac{d T}{d \mathrm{Fo}_{\mathrm{O}}}\right)_{\text {max }} .
$$

If $T(t)=T_{o}+g t$, then

$$
\mathrm{Pd}=\frac{g r^{2}}{a} .
$$

Then, the solution can be presented as

$$
\begin{aligned}
\frac{\Delta T_{m}}{\mathrm{Pd}}= & \frac{T_{m}(y, t)-T_{o}}{\mathrm{Pd}} \\
= & \mathrm{Fo}-0.5\left(1+\frac{2}{\mathrm{Bi}}-\frac{y^{2}}{r^{2}}\right) \\
& +\sum_{n=1}^{\infty} \frac{A_{n}}{\mu_{n}^{2}} \cos \left(\mu_{n} \frac{y}{r}\right) \exp \left(-\mu_{n}^{2} \mathrm{Fo}\right) .
\end{aligned}
$$

Thus, the relative temperature in any point of compact material in thermal deformation zone is the function of nondimensional values $\mathrm{Fo}, \mathrm{Bi}$, and $y / r$. At the axes of the compact material, that is, at $y=0,(35)$ can be presented as

$$
\frac{\Delta T_{m}}{\mathrm{Pd}}=\mathrm{Fo}-0.5\left(1+\frac{2}{\mathrm{Bi}}\right)+\sum_{n=1}^{\infty} \frac{A_{n}}{\mu_{n}^{2}} \exp \left(-\mu_{n}^{2} \mathrm{Fo}\right) .
$$

In this point, the temperature of compact material is minimal.

Knowing the distribution of temperature fields along the length of compact material in thermal deformation zone, required current pulse can be calculated as

$$
I=\sum_{i=1}^{\infty} \sqrt{\frac{T \pi^{2} x_{i} h_{x i} \lambda c g}{r \delta t_{i}}} .
$$

Presented set of analytical descriptions made the complete algorithm for the numerical one-dimensional mathematical modeling of electric contact surfacing for parts such as bodies of rotation by a compact material. The aggregated block diagram of this solutions algorithm is shown in Figure 3. The software for calculation of the power-energy and thermal operating parameters of the electric contact surfacing is developed using the aggregated block diagram. As an example of the received software resources, the calculated distributions of the local and integral characteristics for electric contact surfacing process are shown in Figures 4-10.

The peculiarity of the proposed mathematical model is the correct consideration of distribution of the thermal characteristics of the compact material along the thermal deformation zone, which significantly affects the forming of welded joint during the surfacing process. The adhesive strength, structural homogeneity, and the geometric parameters of the coating are the quality indicators of the surface 


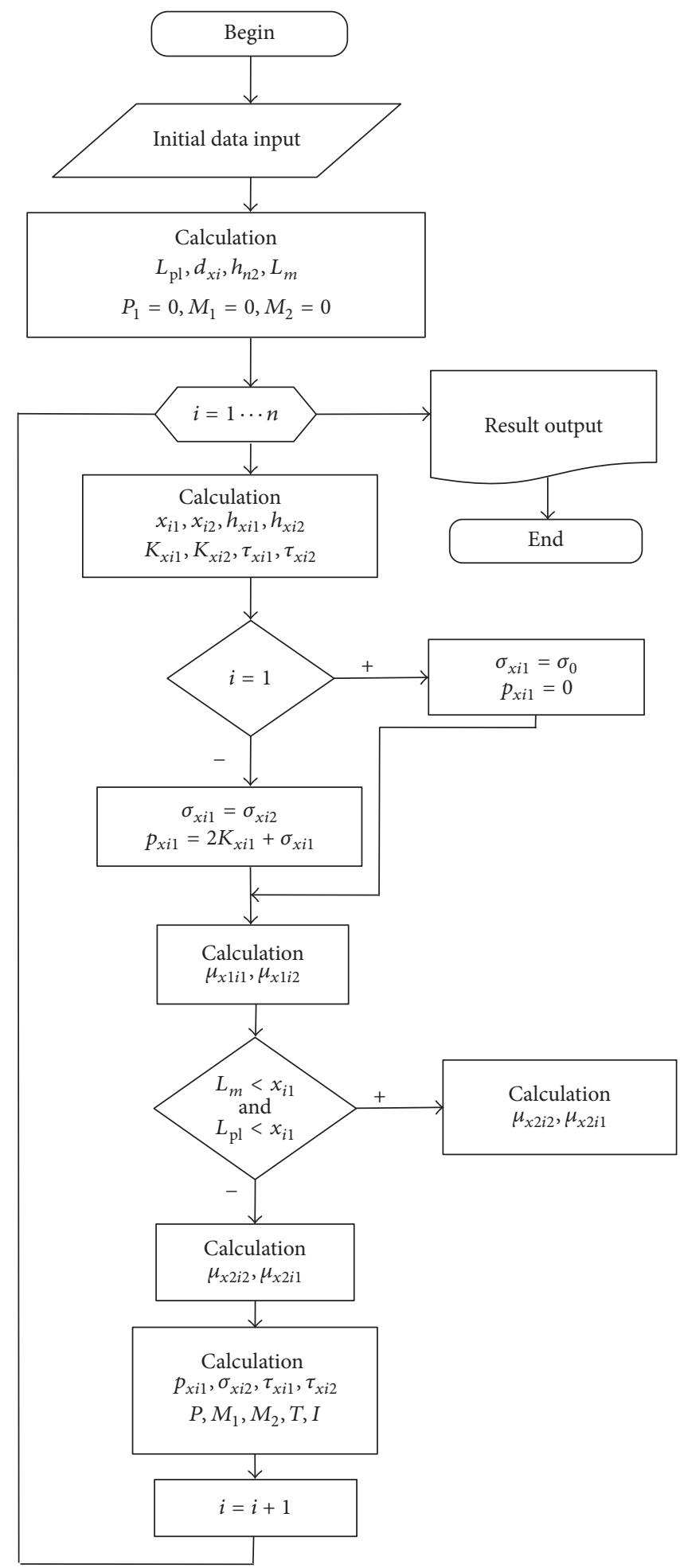

FIGURE 3: The aggregated block diagram of the algorithm for electric contact surfacing by the compact material.

layer. The durability of the restored part directly depends on the adhesive strength of the coating to the part. Because of the low adhesive strength, there is exfoliation of the deposited layer during operation. Therefore, the development of the technological scheme to improve the adhesive strength of the coating is the actual task, which allows providing the forming of the high quality coating.

The important characteristic of electric contact surfacing is the short duration of the heat process. Therefore, the desired thickness of the deposited layer and the high adhesive 


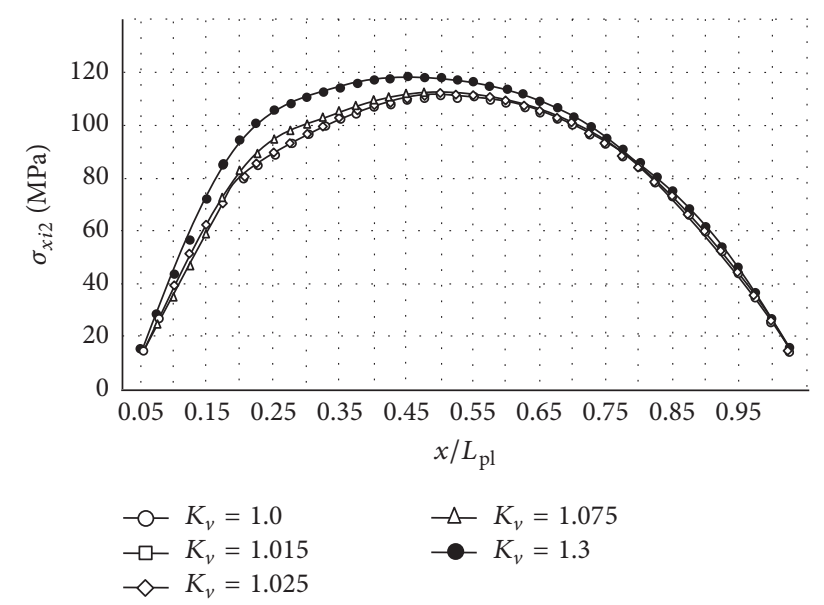

FIgURE 4: The calculated distributions of normal contact stresses along the zone of the surfacing, depending on the speed asymmetry coefficient (the initial thickness of compact material is $0.5 \mathrm{~mm}$ ).

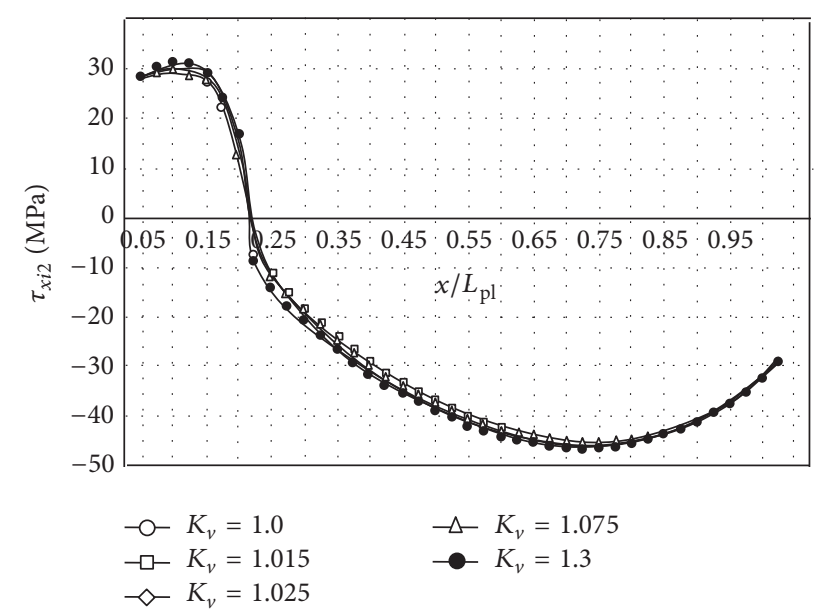

FIGURE 5: The calculated distributions of tangential contact stresses on the roller electrode along the zone of the surfacing, depending on the speed asymmetry coefficient (the initial thickness of the compact material is $0.5 \mathrm{~mm}$ ).

strength of bond by controlling the technological modes of electric-welding process are very important. One of the widely known methods of the bond strength of the coating improving is intensification of the electric contact surfacing by increasing the friction coefficient in the zone of contact of part with compact material due to creation of opposite torque under a current pulse [21]. There is a significant influence on the friction coefficient changing in the zone of electric contact surfacing of the asymmetry of the process at the expense of the controlled changing of kinematic (the rotation speed of the roller electrode and the part), tribological (changing of the friction coefficient, caused by the differences of the roughness of the surfaces), and physical and mechanical (changing of the temperature along the thermal deformation zone) properties. The ratio of linear speeds between the roller electrode and the detail is the most effective method

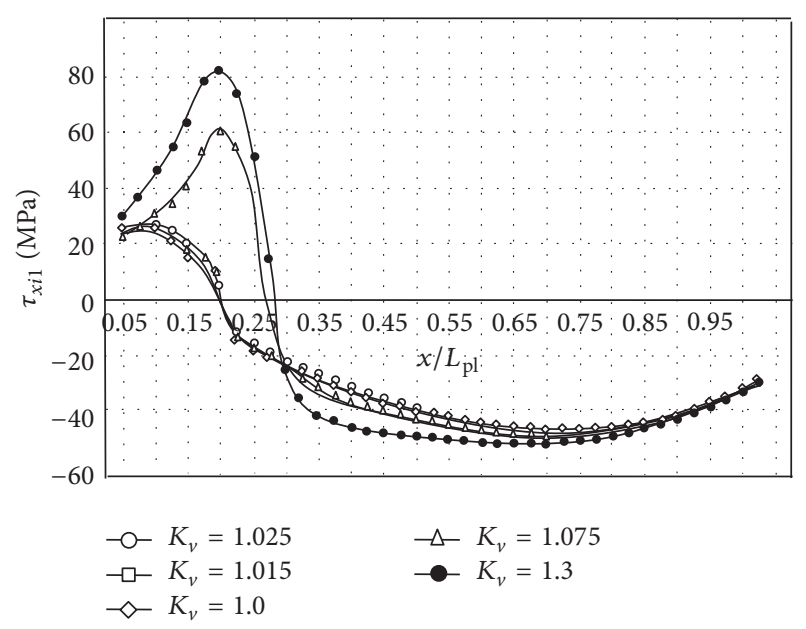

FIgURE 6: The calculated distributions of tangential contact stresses on the detail along the zone of surfacing, depending on the speed asymmetry coefficient (the initial thickness of the compact material is $0.5 \mathrm{~mm}$ ).

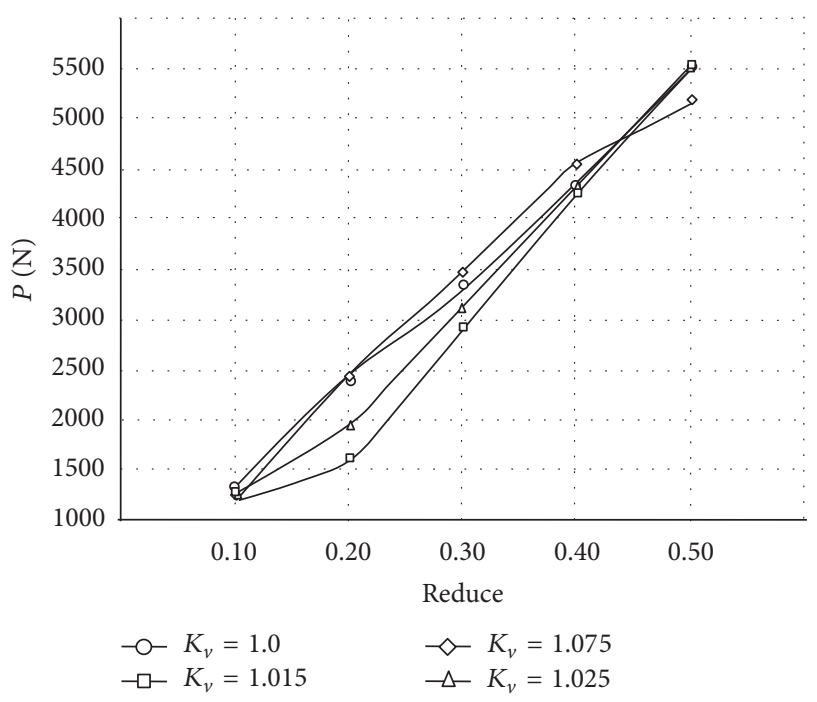

FIgURE 7: The calculated distributions of forces on the roller electrode, depending on the reduce and the speed asymmetry coefficient (the initial thickness of the compact material is $0.5 \mathrm{~mm}$ ).

to manage the asymmetry factor allowing for increasing the friction coefficient.

The theoretical researches were conducted at various values of the speed asymmetry factor $\left(K_{v}=1.0 \cdots 1.075\right)$ and also at various values of reduce $(\varepsilon=0.10 \cdots 0.60)$ during the electric contact surfacing. The calculated distributions of the local and integral characteristics of the electric contact surfacing process are received. Presented graphic dependencies (Figures 4-10) show the influence of the asymmetry factor $K_{v}$ on the coating forming. To ensure the optimal forming of the coating, it is necessary to create the kinematic asymmetry coefficient $K_{v}$, for increasing the tangential contact stresses in the zone of contact between the part and compact material. 


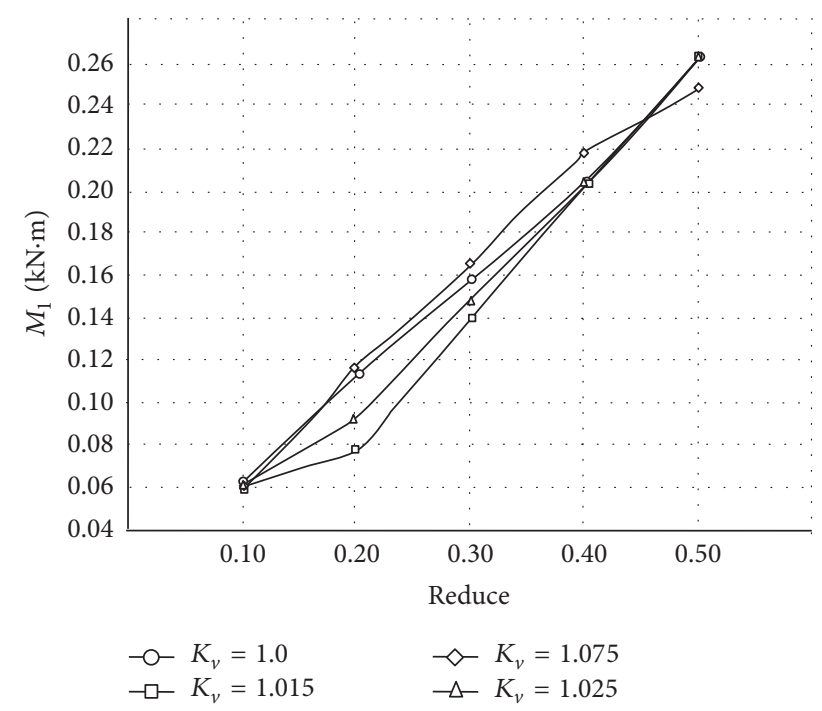

Figure 8: The calculated distributions of the moment on the detail, depending on the reduce and the speed asymmetry coefficient (the initial thickness of compact material is $0.5 \mathrm{~mm}$ ).

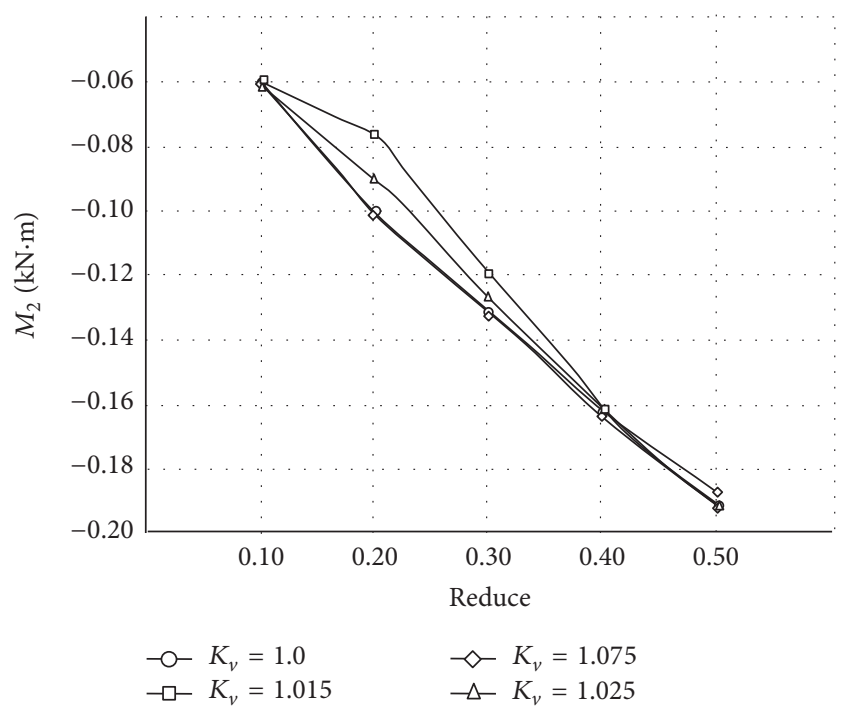

FIGURE 9: The calculated distributions of the moment on the roller electrode, depending on the reduce and the speed asymmetry coefficient (the initial thickness of compact material is $0.5 \mathrm{~mm}$ ).

From the diagram (Figure 6), it is clear that maximum tangential stresses and hence the maximum friction coefficient in the zone of the electric contact surfacing are observed at $K_{v}=1.3$. At equality of the linear rates of roller electrode and cylindrical part, in the absence of asymmetry in the process of electric contact surfacing, tangential stresses on the roller electrode and on the product are equal. Increase of $K_{v}$ leads to the increase of the tangential contact stresses in surfacing zone. Herewith, the friction coefficient on the roller electrode does not change significantly (Figure 5). Because the tangential contact stresses change their value depending on the metal flow direction, the most favorable conditions for the formation of functional layer are observed in the presence

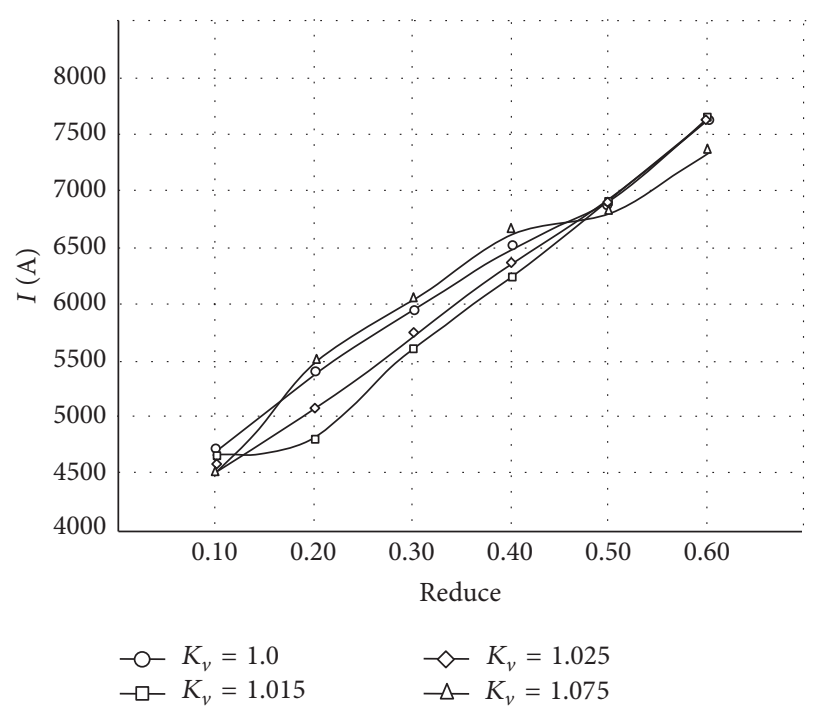

FIGURE 10: The calculated distributions of the current pulse, depending on the reduce and the speed asymmetry coefficient (the initial thickness of compact material is $0.5 \mathrm{~mm}$ ).

of kinematic asymmetry in the process of electric contact surfacing (Figure 6). The areas with the maximum normal contact stresses (Figure 4) match the zero values of the tangential contact stresses (Figure 6). However, the impact of the asymmetry factor on the technological parameters is ambiguous. Figures 7-9 show that with the increasing of kinematic asymmetry coefficient the force on the roller electrode necessary to form surface layer of a given thickness on the product and the moment on the roller electrode parameters depending on the size of the recoverable parts and on the thickness of the coating are changed. Besides, at the $K_{v}=$ 1.015-1.025, the effort on the roller electrode and moments $M_{1}$ and $M_{2}$ are decreased, but increasing the value 1.075, there is the rise in energy-power parameters. Such consistent pattern is traced for the all graphic dependencies (Figures 79) in the range of values of reduce from 0.15 to 0.45 . At reduce of more than 0.45 , the asymmetry factor $K_{v}=1.015 \cdots 1.025$ does not affect the energy-power parameters' changing. Since the impact of the energy-power and operating thermal parameters is simultaneous, the aforesaid consistent pattern is typical also for the dependence of current pulse on the reduce (Figure 10). At the expense of the increasing of asymmetry factor (above $K_{v}=1.075$ ), the values of the energy-power and thermal parameters are decreasing only at value of the reduce of more than 0.45 . The application of such values of the reduce during the electric contact surfacing leads to significant structural changes of the compact material and also to forming the burnouts and splashes. Besides, the application of the high reduce provides forming of the indentations on the surface of coating, which significantly impairs the product appearance. The values of the reduce of $0.20 \cdots 0.30$ are the most expedient for the conditions of the electric contact surfacing, which provides the forming of the coating with desired performance characteristics. Thus, the application of the speed asymmetry factor above 1.075 is inexpedient for the conditions of electric contact surfacing by compact material 


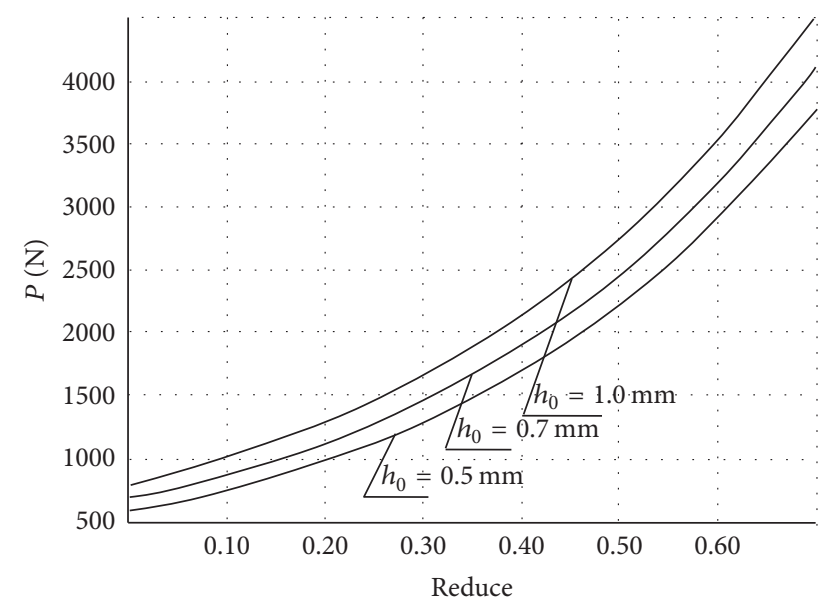

FIGURE 11: The results of automated design of the efforts on the roller electrode, depending on reduce. $R 1=50 \mathrm{~mm} ; a_{1}=0.124 ; a_{2}=$ $0.052 ; a_{3}=-3.70 ; \sigma_{\tau 0}=60.1 \mathrm{~N} / \mathrm{mm}^{2} ; \lambda=0.26$.

with reduce of $0.15 \cdots 0.30$ because of increasing of the energy intensity of the process.

So, the most rational in terms of the quality of the coating is the asymmetrical electric contact surfacing process with speed asymmetry of not more than 1.015. This allows providing the increase of the friction coefficient in the surfacing zone without the increase of the energy and power parameters. Reduction of the integral characteristics of the process allows repairing big sized parts with the lowest thermal and mechanical impact. This minimizes the structure changes of the functional coating and the surface layer of main metal. On the basis of the developed software, the calculation of the main technological process parameters was made (Figures 11 and 12). From a practical point of view, the results of the automated design of technological modes of electric contact surfacing by the compact material allow identifying all the initial parameters of the process to produce a specified thickness of the coating on the surface of the part.

\section{Experimental Studies}

The check of the adequacy of the obtained analytical descriptions of electric contact surfacing was done during restoring of the parts of "shaft" type made of steel St 45 by continuous ribbon St 45 on the electric machine of the seam type welding MSHP-150 with a rated power of the surfacing current $20 \mathrm{kA}$ and a maximum compression force of $8 \mathrm{kN}$ (Figure 13(a)).

Force measurement on the roller electrode was done with the help of load cells; also the measurement of the moments on the roller electrode and the detail was provided with the help of tensiometric sensor of resistance. Using the sliding strings of current collectors, the electrical signal from the rotating universal spindles was read. The calibration of the measuring instruments was performed by simulation of loading with the use of the cantilever arm and a set of cargos. Recording of registered parameters was produced by means of a PC with built-in analog-to-digital converter, providing the measuring ability at 16 differential channels. Input in this case is digitized by 16-bit analog-digital converter with

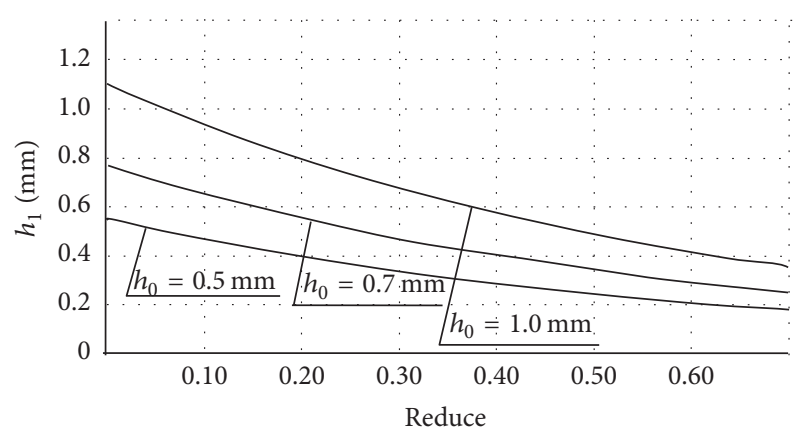

FIGURE 12: The results of automated design of the final thickness of the coating, depending on the reduce. $R 1=50 \mathrm{~mm} ; a_{1}=0.124 ; a_{2}=$ $0.052 ; a_{3}=-3.70 ; \sigma_{\tau 0}=60.1 \mathrm{~N} / \mathrm{mm}^{2} ; \lambda=0.26$.

a frequency of $100 \mathrm{kHz}$ and a gain opportunity in the range of 1 to 1000 . The oscillograms were recorded by a converter of voltage measuring E14-140 (Figure 13(b)). The converter is designed to perform tasks with feedback signals. Monitoring, recording, and analysis of the recorded data were done by the software Usb Oscilloscope (version 3.1.2.8) at a scale of 1:20; each oscillation is the time period of $0.02 \mathrm{~s}$.

The control of geometric parameters of the initial compact materials and the received coating was carried out by a micrometer and caliper. The results of comparison of the calculated and experimental distributions of the efforts on the roller electrode are presented in the form of graphic dependence (Figures 14 and 15).

The integral characteristics of the process of electric contact surfacing by compact materials are determined in investigation. This allows making conclusion about sufficient convergence of experimental results and theoretical assumptions concerning process laws. The change of speed asymmetry factor is the perspective direction for control of the stressstrained state of compact material, which allows regulating the plastic deformation of the material process. The optimum conditions for forming of wearproof coating without lack of fusion can be obtained by changing the speed asymmetry factor which depends on rotational speed ratio of roller electrode and "shaft" type parts.

\section{Discussion}

The heavy operating conditions lead to fast deterioration of details durability. Increasing of technical and economic parameters of equipment is inextricably linked with increasing of service life of parts working in conditions of intense abrasive deterioration. Restoration of operability of worn equipment can be achieved by two ways: either changing of worn parts by new ones or building up of metal on worn surface until reaching the nominal sizes. The first way is less profitable from economic point of view because the expenses on spare parts can achieve $80 \%$ of initial cost of equipment. The electric contact surfacing by compact materials allows applying on the worn surface a coating of the specified thickness with the required operating characteristics. Use of this method allows solving effectively the problem of prolonging of service term of technological unit. The 


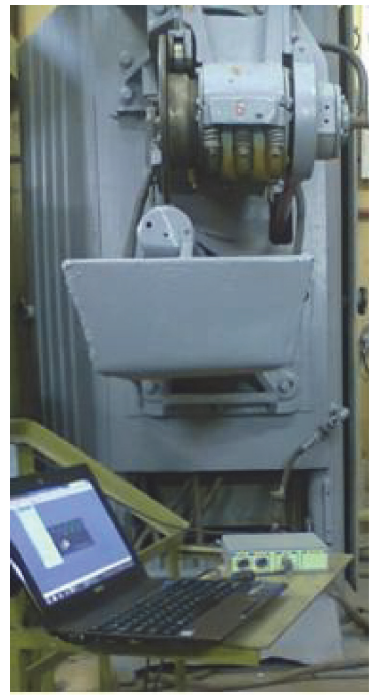

(a)

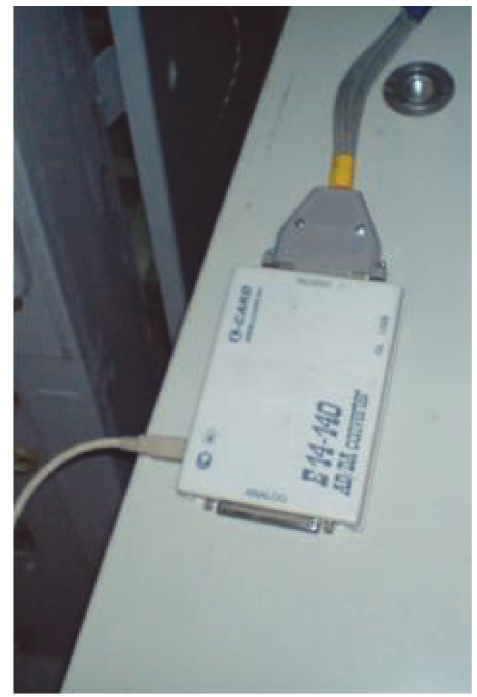

(b)

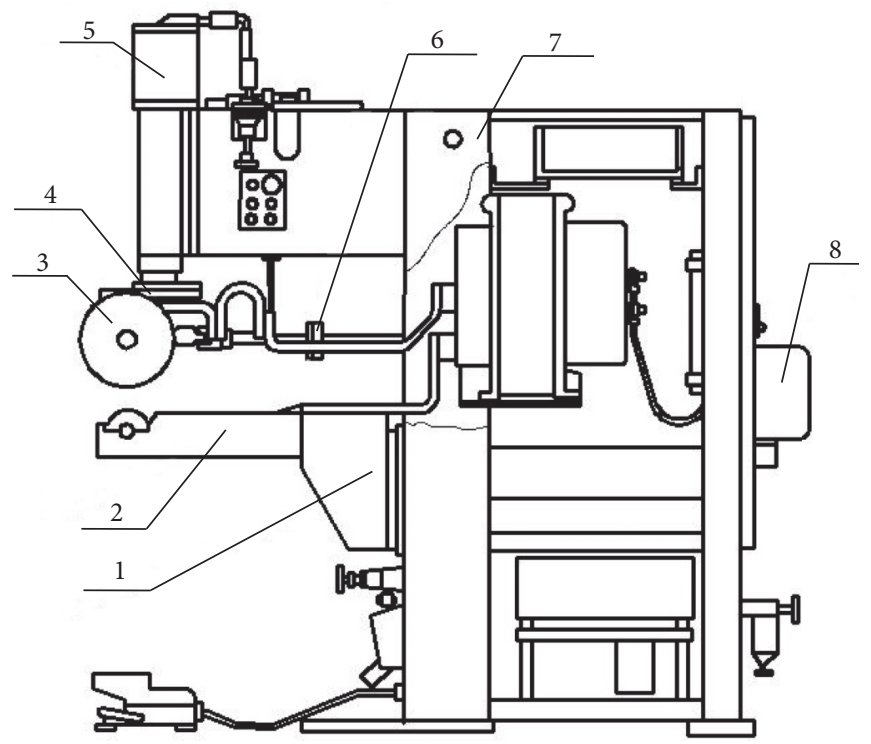

(c)

FiguRE 13: General view of the installation for experimental investigation (a, b), the basic scheme of equipment for electric contact surfacing (c) (1: bottom bracket, 2: cantilever, 3: roller electrode, 4: intermediate plate, 5: slider for drive efforts, 6: articulated shaft, 7: casing wall, and 8: the rotary drive).

method of electric contact surfacing is characterized by transience of intensely thermomechanical impact on the surfacing compact material. This allows obtaining coating on the surface of part without significant thermal influence on the base metal of part. This peculiarity of the process allows avoiding the structural changes of the base metal and preventing decreasing of its mechanical properties. However, the transience of current pulse confines the precision of quality prediction of the coating. The adhesive strength of the deposited coating is the most important quality indicator because at the low value of this parameter there is exfoliation of the coating during operation. The intensification of the surfacing process at the expense of increasing of the friction coefficient in zone of contact of part with compact material is an effective method to improve the adhesive strength of the coating. The speed asymmetry factor has a great influence on increasing of friction coefficient in surfacing zone. The change of this parameter has a significant impact on stress-strain state of compact material in thermal deformation zone.

The influence of speed asymmetry factor on the local and integral characteristics of the process is considered in present work (Figures 4-9). The calculated distributions of normal contact stresses illustrate the behavior of material in a case of symmetric and asymmetric electric contact surfacing.

Increase of the speed asymmetry factor leads to change of stress-strain state of the compact material in thermal deformation zone. Increase of $K_{v}$ above 1.3 provides also the significant increase of tangential contact stresses (maximum 

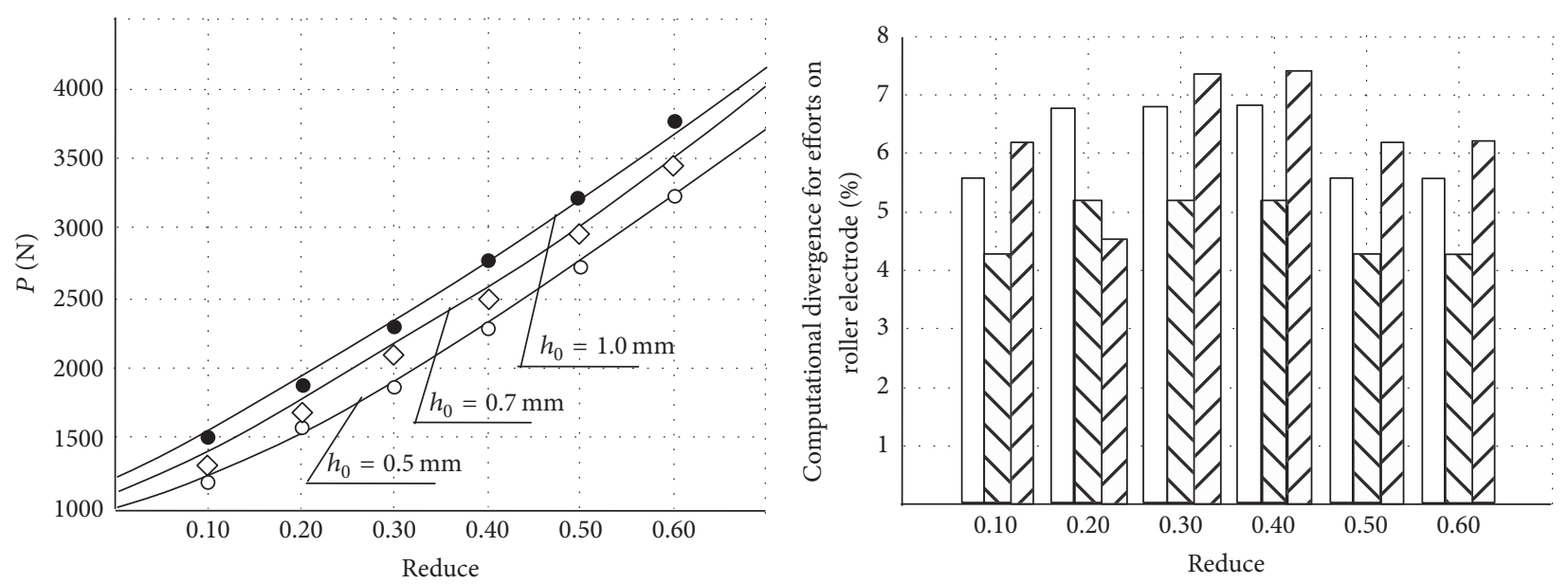

$$
\begin{aligned}
& \bigcirc h_{0}=0.5 \mathrm{~mm} \\
& \diamond h_{0}=0.7 \mathrm{~mm} \\
& \text { - } h_{0}=1.0 \mathrm{~mm}
\end{aligned}
$$$$
\begin{aligned}
& \square h_{0}=0.5 \mathrm{~mm} \\
& h_{0}=0.7 \mathrm{~mm} \\
& \text { एाय } h_{0}=1.0 \mathrm{~mm}
\end{aligned}
$$

(a)

(b)

FIGURE 14: The calculated and the experimental distributions of the efforts on the roller electrode during the electric contact surfacing by the compact material. $R 1=50 \mathrm{~mm} ; a_{1}=0.124 ; a_{2}=0.052 ; a_{3}=-3.70 ; \sigma_{\tau 0}=60.1 \mathrm{~N} / \mathrm{mm}^{2} ; \lambda=0.26$.

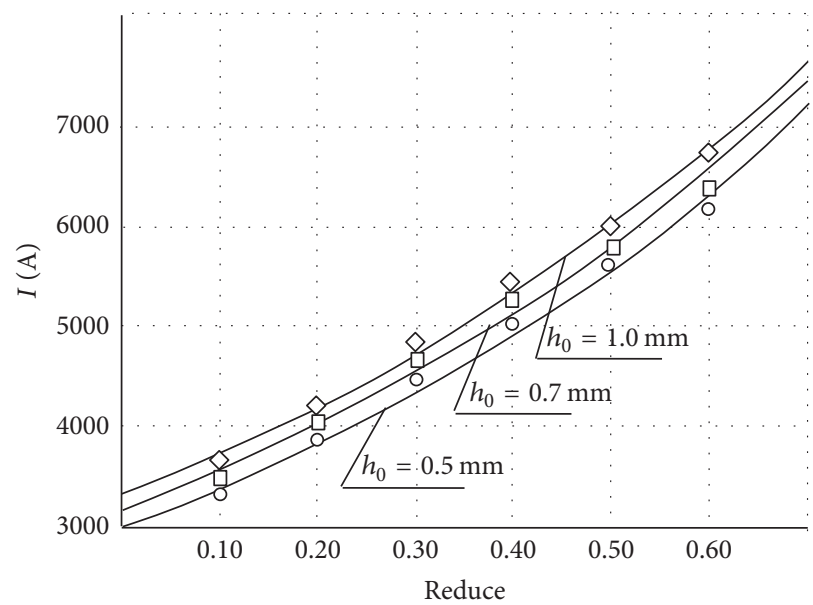

○ $h_{0}=0.5 \mathrm{~mm}$

$\square h_{0}=0.7 \mathrm{~mm}$

$\diamond h_{0}=1.0 \mathrm{~mm}$

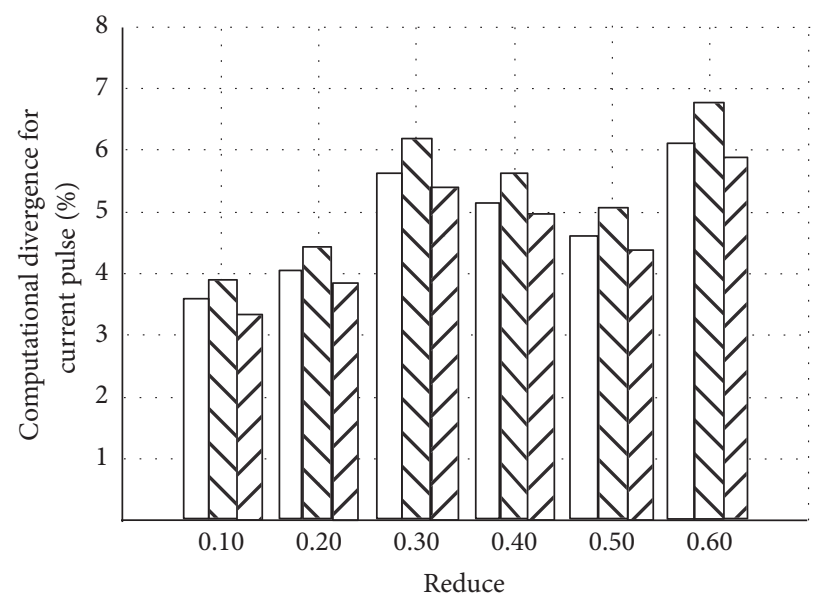

$h_{0}=0.5 \mathrm{~mm}$
$h_{0}=0.7 \mathrm{~mm}$
$h_{0}=1.0 \mathrm{~mm}$

(a)

(b)

FIGURE 15: The calculated and the experimental distributions of the current pulse during the electric contact surfacing by the compact material. $R 1=50 \mathrm{~mm} ; a_{1}=0.124 ; a_{2}=0.052 ; a_{3}=-3.70 ; \sigma_{\tau 0}=60.1 \mathrm{~N} / \mathrm{mm}^{2} ; \lambda=0.26$.

values of the tangential contact stresses $\tau_{x i 1}=83.7 \mathrm{MPa}$ at $K_{v}=1.3$ and $\tau_{x i 1}=25.6 \mathrm{MPa}$ at $K_{v}=1.0$ ). This allows increasing friction coefficient in surfacing zone, which leads to enhancement of the quality of the coating forming. The friction coefficient and the tangential contact stresses on the roller electrode practically do not change. Thus, adhesion between the compact material and the roller electrode does not occur. However, such an increase of the speed asymmetry factor leads to increase of the energy and power parameters of the process. Increasing of the effort on the roller electrode occurs at $K_{v}=1.075$ (for $\varepsilon=0.30$ at $K_{v}=$ 1.0 , the effort on the roller electrode is about $3400 \mathrm{~N}$; at $K_{v}=1.015,3000 \mathrm{~N}$; at $K_{v}=1.075,3500 \mathrm{~N}$ ). The regulation of the speed asymmetry factor allows for expanding the technological capabilities of equipment for electric contact surfacing whose limitations are associated with the size of 
recoverable parts and application of high electromechanical powers.

The calculation of the main technological parameters of the process is received with application of developed software. Via developed software, the value of speed asymmetry factor was calculated, which allows increasing friction coefficient in thermal deformation zone. The nomograms for determination of the stress on the roller electrode (Figure 10) and the finite thickness of the coating (Figure 11) depending on the initial thickness of the compact material and deformation degree are presented. The automated design of technological process allows obtaining recommendations for selection of optimal operating parameters. The experimental verification of adequacy of the developed mathematical model which confirms satisfactory agreement of calculated data with experimental is performed.

Generally, the obtained results confirm that the variation of initial parameters of electric contact surfacing process of cylindrical parts is very important during the formation of power parameters, as well as during preparation of measures aimed at ensuring the stability of the surfacing process and improving the quality of the deposited layer with specified geometrical characteristics.

\section{Conclusion}

A mathematical model, which allows optimizing the technological parameters of electric contact surfacing by compact material of the "shaft" type parts, was developed. As a result of numerical implementation of the developed model, it was found that a significant effect on the change of power parameters of the process was made by the ratio of roller electrode and the "shaft" type parts speeds. It is established that the change of the speed asymmetry factor has a significant influence on the forming of the coating because of the increasing of the friction coefficient. It is proved that the application of the asymmetric process of electric contact surfacing allows decreasing the thermomechanical impact on the compact material in surfacing zone. This considerably expanded the capabilities of the equipment and allows reducing the thermomechanical influence on the base metal of the parts. Obtained graphic dependences allow determining the initial parameters of the process such as the amperage, stress on the roller electrode, and the initial thickness of the compact material, depending on the required characteristics of the coating before the beginning of the process of electric contact surfacing.

\section{Nomenclature}

$x_{i 1}, x_{i 2}$ : Geometric coordinates of initial and finite boundary section of selected elementary volume

$V_{2}, V_{1}: \quad$ Rotational speed of roller electrode and part

$R_{b 2}, R_{b 1}$ : Radius of roller electrode and part

$L_{\mathrm{pl}}$ : $\quad$ Length of the zone of the plastic deformation

$L_{m}: \quad$ Length of the mixed zone
$L_{\lg 2}$ : Length of the zone of the lag on the roller electrode

$\Delta x: \quad$ The value of the partition step of the plastic deformation zone

$2 K_{x}: \quad$ Current value of the double shift resistance of the compact material along the length of thermal deformation zone defined with considering of the current values of degree, velocity, and temperature of deformation

$p_{x 1}, p_{x 2}$ : Normal contact stresses on the roller electrode and on the part

$h_{x i 1}, h_{x i 2}: \quad$ Current values of thickness of the coating along the length of selected elementary volume

$h_{0}$ : Initial thickness of the compact material

$h_{1}$ : $\quad$ Final thickness of the coating

$h_{n 2}$ : Thickness of the compact material in the neutral section

$a_{h}$ : Exponent indicator of the real convex shape of the roller electrode

$b$ : $\quad$ Width of the roller electrode

$P: \quad$ Stress on the roller electrode

$M_{1}, M_{2}$ : Moment on the part and on the roller electrode

$T_{o}: \quad$ The environment temperature

$T_{m}: \quad$ The material temperature

$a: \quad$ Coefficient of temperature conductivity

$r$ : The half of the thickness of compact material

$a_{\mu 1}, a_{\mu 2}: \quad$ The exponent characterizing the distribution of the plastic friction coefficients on the contact surfaces of the part and the roller electrode

$\mathrm{Bi}=\alpha r / \lambda:$ Biot criterion

$\mathrm{Fo}=a t / r^{2}:$ Fourier criterion

Pd: $\quad$ Predvoditelev criterion

I: $\quad$ The current pulse.

Greek Letters

$\tau_{x 2}, \tau_{x 1}$ : Tangential contact stresses on the roller electrode and on the part

$\sigma_{0}: \quad$ Rear tension stress of the compact material

$\sigma_{1}$ : Normal axial stresses in the outlet of thermal deformation zone

$\mu_{x 1}, \mu_{x 2}$ : Current value of plastic friction coefficient

$\lambda: \quad$ Coefficient of thermal conductivity

$\alpha$ : Heat transfer coefficient.

Index

$i$ : The current ordinal number of the selected elementary volume along the length of the thermal deformation zone

$n$ : The number of partitions along the length of thermal deformation zone

1: The value at the entrance to the elementary volume of thermal deformation zone

2: The value at the output from an elementary volume of thermal deformation zone. 


\section{Disclosure}

The submission of the authors' paper implies that it has not been previously published, that it is not under consideration for publication elsewhere, and that it will not be published elsewhere in the same form without the written permission of the editors.

\section{Competing Interests}

The authors Olena V. Berezshnaya, Eduard P. Gribkov, and Valeriy D. Kuznetsov declare that there is no conflict of interests regarding the publication of this paper.

\section{Authors' Contributions}

All authors participated in the design of this work equally. All authors read and approved the final manuscript.

\section{References}

[1] L. Jin-Gui, "Surface hardening technologies and mouldsurvice life," China Surface Engineering 1, 2002.

[2] L. Pawlowski, The Science and Engineering of Thermal Spray Coatings, John Wiley \& Sons, New York, NY, USA, 2nd edition, 2008.

[3] J. Winczek, G. Rygał, and T. Skrzypczak, "The model of temporary temperature field during multi-pass arc weld surfacing. Part I: analytical description," Journal of Applied Mathematics and Computational Mechanics, vol. 14, no. 2, pp. 123-130, 2015.

[4] H.-J. Kim and Y. J. Kim, "Wear and corrosion resistance of PTA weld surfaced $\mathrm{Ni}$ and CO based alloy layers," Surface Engineering, vol. 15, no. 6, pp. 495-501, 1999.

[5] J. Winczek, "Modelling of heat affected zone in cylindrical steel elements surfaced by welding," Applied Mathematical Modelling, vol. 36, no. 4, pp. 1514-1528, 2012.

[6] C. Wallace, "Submerged arc welding method for steel sheets," Patent EP 2786829 A1, 2012.

[7] Kh. N. Sagirov, D. Kh. Sagirov, S. D. Khachkinaev, S. K. Slitinskaya, N. G. Dyurgerov, and D. P. Perfil'ev, "Efficient process of automatic submerged-arc surfacing," Welding International, vol. 18, no. 2, pp. 121-123, 2004.

[8] V. L. Kvanin, N. T. Balikhina, V. G. Karabakhin, and A. G. Merzhanov, "Deposition of protective coatings by combined SHS/argon-arc surfacing," International Journal of Self-Propagating High-Temperature Synthesis, vol. 20, no. 2, pp. 88-93, 2011.

[9] V. V. Bulychev and V. V. Zezyulya, "Electrical resistance deposition with a wire and deceleration of the roller electrode," Welding International, vol. 25, no. 5, pp. 374-377, 2011.

[10] R. N. Saifullin and V. S. Natalenko, "A method of production of sintered strips by electric resistance rolling," Welding International, vol. 25, no. 3, pp. 205-208, 2011.

[11] P. I. Burak, A. V. Serov, and R. A. Latypov, "Optimization of the process of electric resistance welding of metallic strips through an amorphous solder," Welding International, vol. 26, no. 10, pp. 814-818, 2012.

[12] M. V. Storozhev and E. A. Popov, Theory of Metal Forming: A Textbook for High Schools, Mashinostroenie, 1977.

[13] E. P. Gribkov, A. V. Perig, and V. A. Danilyuk, "Research into the process of producing powder tapes," International Journal of
Advanced Manufacturing Technology, vol. 77, no. 5-8, pp. 10871104, 2015.

[14] O. V. Berezshnaya and E. P. Gribkov, "Matematicheskoe modelirovanie formoobrazovaniya sloya pri electrocontaktnoi naplavke provolokoi detalei typa 'val,' Visnik of the Volodymyr Dahl East Ukrainian National University, vol. 6, no. 213, pp. 93-96, 2014 (Russian).

[15] C. Bartuli, T. Valente, and M. Tului, "Plasma spray deposition and high temperature characterization of $\mathrm{ZrB}_{2}-\mathrm{SiC}$ protective coatings," Surface and Coatings Technology, vol. 155, no. 2-3, pp. 260-273, 2002.

[16] R. N. Saifullin, "Improvement of performance of machine parts by electrocontact welding of composite materials," Journal of Friction and Wear, vol. 28, no. 2, pp. 206-211, 2007.

[17] A. D. Koval', V. G. Efremenko, M. N. Brykov, M. I. Andrushchenko, R. A. Kulikovskii, and A. V. Efremenko, "Principles for developing grinding media with increased wear resistance. Part 1. Abrasive wear resistance of iron-based alloys," Journal of Friction and Wear, vol. 33, no. 1, pp. 39-46, 2012.

[18] R. N. Saifullin, "Improvement of performance of machine parts by electrocontact welding of composite materials," Journal of Friction and Wear, vol. 28, no. 2, pp. 206-211, 2007.

[19] K. D. Voskresenskiy, Sbornik Raschetov I Zadach Po Teploperedache, Collection of Calculations and Heat Transfer Problems, Ripol Classic, 2013 (Russian).

[20] A. I. Veinik, Priblizhennyj Raschet Protsessov Teploprovodnosti, Ripol Classic, 2013 (Russian).

[21] V. V. Zezulia and V. V. Booluchev, "Method of electric contact surfacing," Patent RU 2466000, 2012 (Russian). 

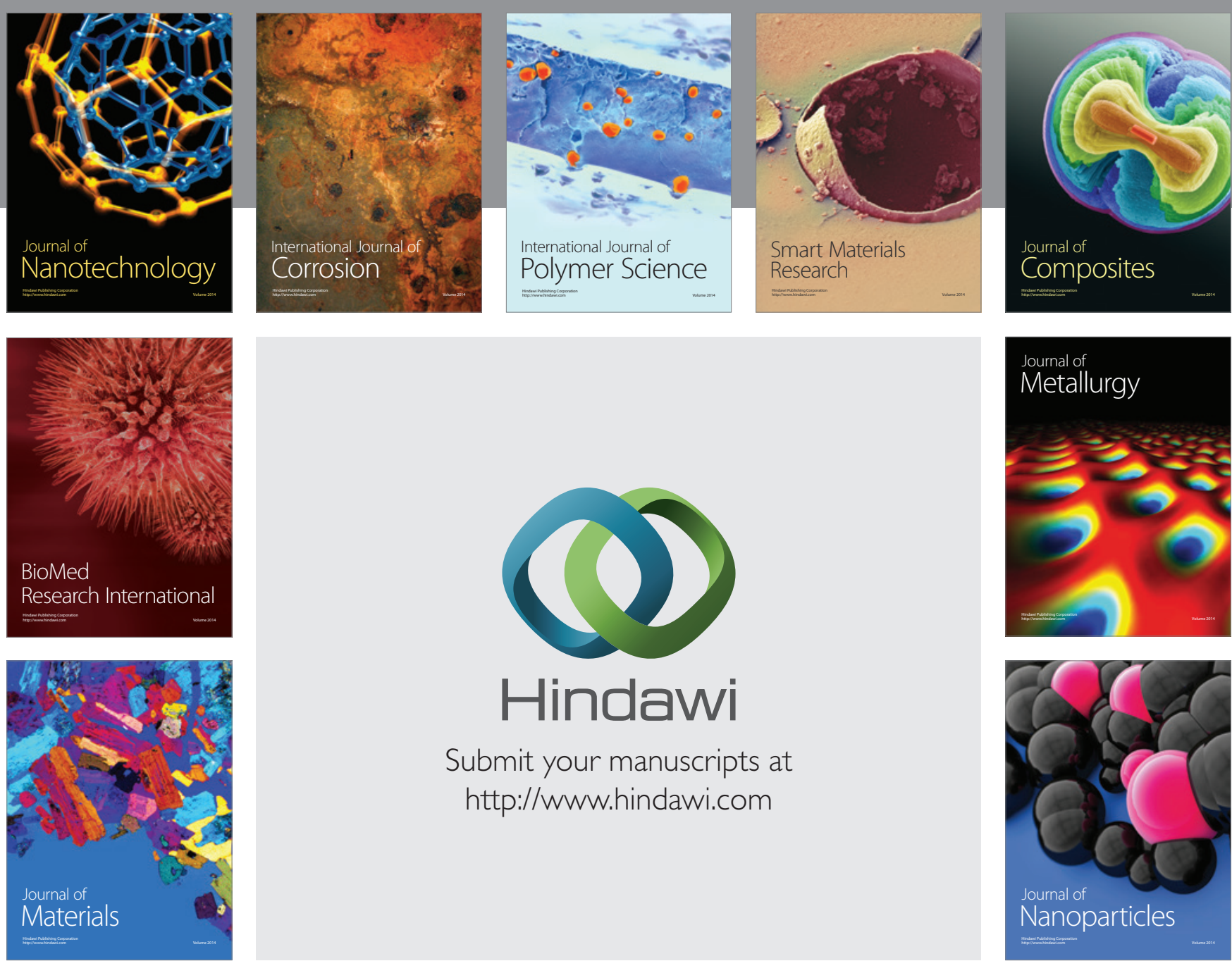

\section{Hindawi}

Submit your manuscripts at

http://www.hindawi.com

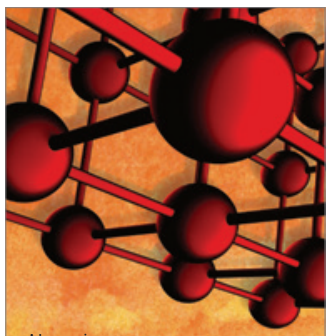

Materials Science and Engineering
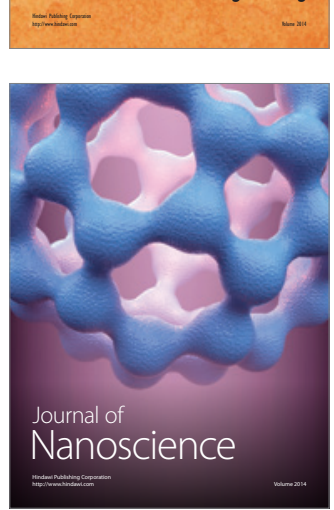
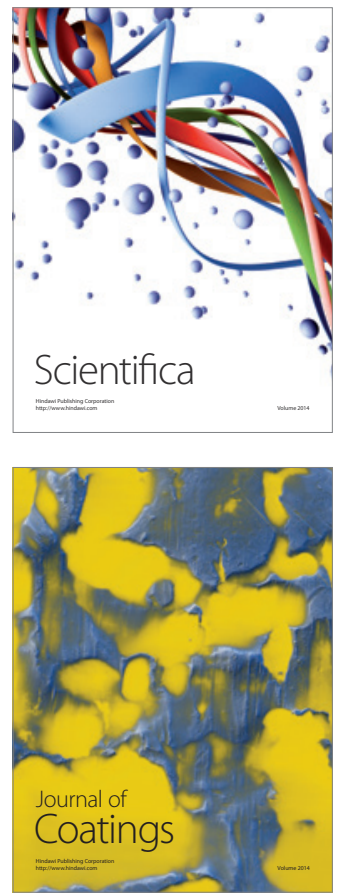
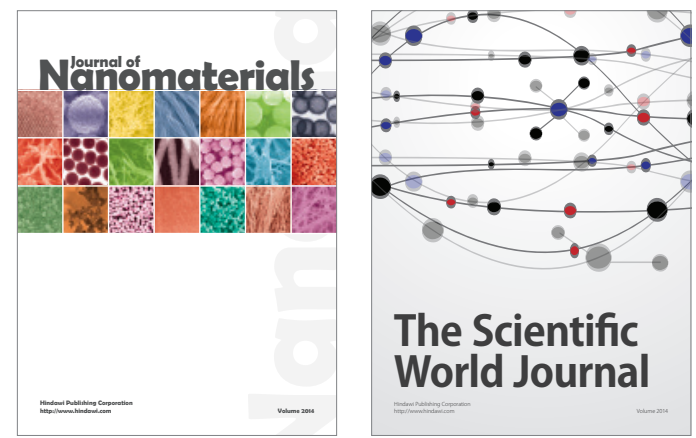

The Scientific World Journal
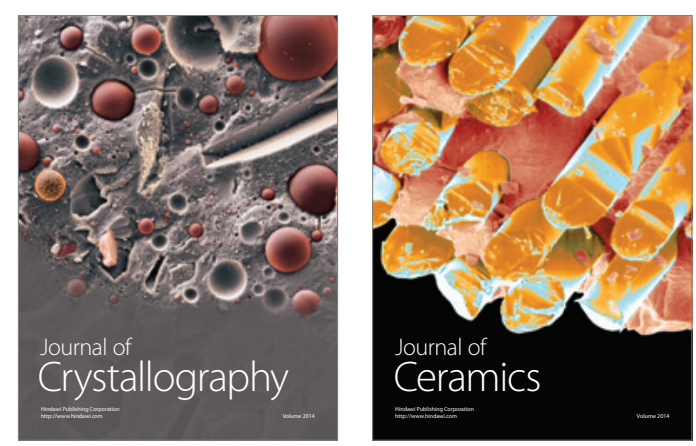
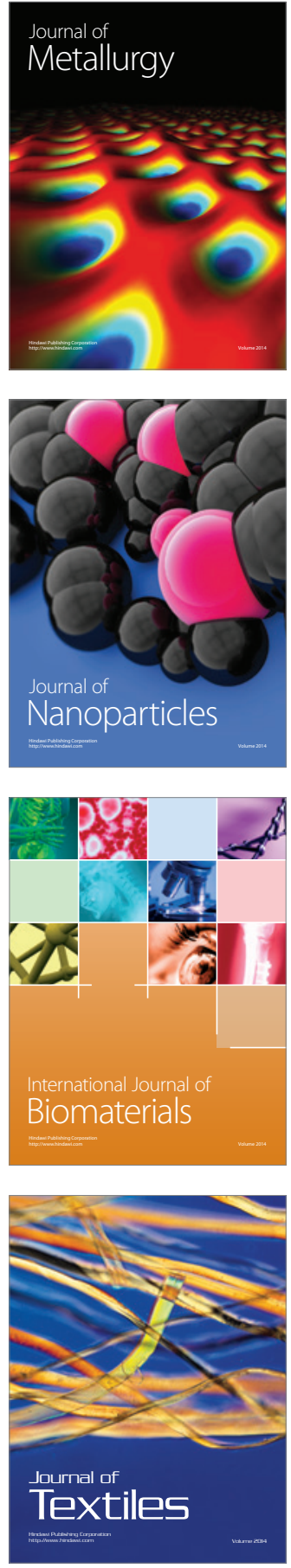